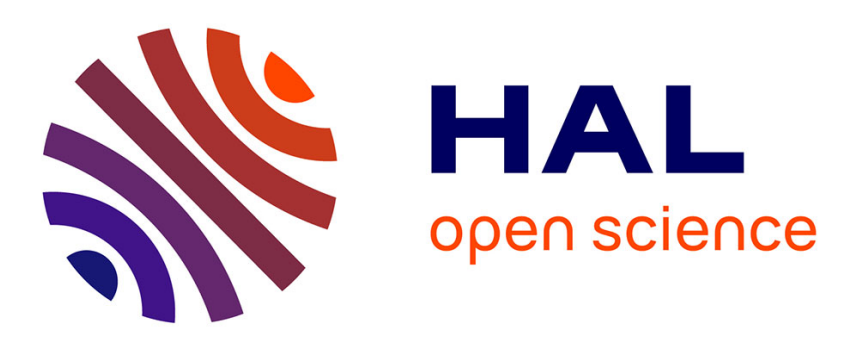

\title{
A Conceptual Perspective on Knowledge Management and Boundary Spanning: Knowledge, Boundaries and Commons
}

Léo Joubert, Claude Paraponaris

\section{- To cite this version:}

Léo Joubert, Claude Paraponaris. A Conceptual Perspective on Knowledge Management and Boundary Spanning: Knowledge, Boundaries and Commons. The Palgrave Handbook of Knowledge Management, Palgrave Macmillan, 2018, 978-3-319-71433-2. halshs-02072131

\section{HAL Id: halshs-02072131}

\section{https://shs.hal.science/halshs-02072131}

Submitted on 18 Mar 2019

HAL is a multi-disciplinary open access archive for the deposit and dissemination of scientific research documents, whether they are published or not. The documents may come from teaching and research institutions in France or abroad, or from public or private research centers.
L'archive ouverte pluridisciplinaire HAL, est destinée au dépôt et à la diffusion de documents scientifiques de niveau recherche, publiés ou non, émanant des établissements d'enseignement et de recherche français ou étrangers, des laboratoires publics ou privés. 


\title{
A Conceptual Perspective on Knowledge Management and Boundary Spanning: Knowledge, Boundaries and Commons
}

\author{
in Syed, J., Murray, P., Hislop, D., Mouzughi, Y. (Eds.) The Palgrave Handbook of \\ Knowledge Management, Palgrave Macmillan, 2018, pp. 323-347.
}

\section{Léo Joubert and Claude Paraponaris}

Aix Marseille Univ, CNRS, LEST UMR 7317, 13626, Aix en Provence, France

\begin{abstract}
Boundaries and transcending boundaries have become a major discussion topic in fields involved in the creation of value in Western economies. Quite often assimilated into physical and cultural limits, boundaries are presented as obstacles to entrepreneurial achievement. This entrepreneurial ability that unfolds in different fields - the economy of course, but also cultural activities, notably through a revolution of usages facilitated by internet business platforms. It seems pertinent to compare how commercial and non-commercial activities process information and accumulate knowledge.
\end{abstract}

Boundaries must be crossed in order to diffuse knowledge and create innovation. But boundaries also act as a protection for scientific, technical, and cultural organisations and institutions. Boundaries are multiple and, in principle, objective between projects, organisations, types of knowledge, scientific disciplines, and of course between the various actors. But are they really all that objective?

The succession of approaches towards knowledge management has a history (Snowden, 2002). A genealogy of the concepts and their success is available, testifying to the plasticity of knowledge boundaries. In this sense, our analysis presents boundaries as a construct that enables association between elements as much as separation.

We begin by presenting a genealogy of the major concepts in the field of knowledge dissemination. We lay down the various terms that refer to knowledge boundaries, insisting, in particular, on the persistent misunderstanding about how the learning process leads to knowledge. This conceptual framework helps us distinguish two functions of a boundary separation and elaboration. We will then go on to develop this distinction for commercial organisations, and finally for non-commercial organisations such as Wikipedia.

\section{How Should the Question of Boundaries Be Analysed in the Field of Knowledge Management?}

\section{A Conceptual Journey}

Evoking the boundary question is closely linked to the development of the role of knowledge transfer. This is a question of strategic thinking focused on the resources required by organisations (Teece, 2009). During the 1990s, the resource-based trend (Wernerfelt 1984) later transformed into the knowledge-based view of the firm (Grant, 1996), and finally dynamic capabilities took over in the strategic analysis of organisations. One of the major authors, David Teece, extensively studied these dimensions, highlighting the role of processes, routines, methods, skills, and decision-making rules in developing the competitiveness of commercial organisations. Among these capabilities, resources such as technical and business knowledge were described as strategic. They received very close attention. Such close attention, in fact, that many analyses transformed them into objects 
distinct from the activities and humans that developed them. This increase in strategic thinking separated itself from sociocognitive approaches (Blumer 1966; Vygotski 1934; Weick 1969), thereby creating an autonomous field of thought. But this empowerment provoked serious misunderstandings that could lead one astray. We summarise the evolution of the concepts and draw on the consequences to define the boundaries in the area of organisational cognition.

\section{Knowing / Knowledge}

An analysis of emerging concepts and their influence in economics is regaining in interest. Studies reveal that the practices of an organisation's members are a complex process (Cabantous and Gond 2010). This process develops under the influence of wider sociohistorical movements that cross the boundaries of firms. This process structures management theories engedered by socio-historical movements that eventually become conventions and tools used to analyse and decide on economic matters, and finally the actions of individuals such as consultants who accompany managers in their decision-making. Snowden (2002) illustrates this type of analysis for the formation of knowledge management concepts. He points out the social methods used in structuring such concepts. An entire set of needs has been aggregated around the notion of "knowledge management" without necessarily appreciating the meaning of this perspective. According to Snowden, knowledge management is an oxymoron. The author strongly criticises the idea that simple will alone is able to identify and transfer knowledge.

Yet the conception of knowledge as an object has become much more important than the processes of learning (knowing). This is a reversal of the possibilities offered by cultural anthropology and ethnomethodology since the mid-twentieth century. The act of "knowing", in fact, finds one of its origins in this field of research. The role of "psychological instruments" highlighted by Vygotski (1934) opened the door to cultural studies of learning. This Russian psychologist revealed that in order to conduct one's activities, the child and then the adult, uses psychological tools among which is the language one speaks. Learning consists in appropriating these psychological tools. Mental activity feeds on words, enabling us to develop concepts. Humans evolve within a "language/thought" system that allows us to develop our cognitive skills. This analysis reveals two important aspects. On the one hand, cognitive activity is completely immersed in language, which is a common good, and on the other, all the cognitive activity of an individual takes place during one's longstanding learning processes. Thus, a dialectic is established between what is appropriated by the individual, and the categories of meaning developed in society. The private and the common evolve in concert.

For the interactionist sociologist Herbert Blumer (1966), meanings develop within social interactions and are tested through an interpretation process by the individual in his relations with the outside world. The context is not an objective fact but it is constantly redefined through interactions. The psychologist Karl Weick $(1969,1986,1993)$ presupposes that the process of attributing meaning leads to forming schemas that guide actions thereafter. The context that is constructed plays a decisive role in reasoning; the individual commits actions based on conceptions he develops (enactment process). Reality is transformed, to a certain extent, by the impact of individual actions. Through a process of selection, the individual can then make this reality intelligible by mobilising the "causal map" he developed through experience. In this way, a situation can become ambiguous (equivocality): It can be interpreted in several ways without becoming ambivalent or confusing. This 'new' reality that has become significant for the individual is stored in the form of a causal map (retention process). 
An array of approaches to organisational cognition was available as early as the 1970s to study knowledge management processes. Analytical tools were available to evaluate the expansion of knowledge and recognise understanding or "knowing". The term "knowing" is used to refer to the epistemological dimension of the action itself. By "knowing", we do not mean something that is used in action or something necessary to action but rather something that is a part of action, both individual and group action" (Cook and Brown, 1999: 387).

While the course of cultural anthropology reveals that knowledge does not exist on its own, and that it presupposes a prior learning experience of the subject, situations and supports such as a language's syntax and semantics - a majority of studies focused on knowledge transfer to the detriment of knowing. This analysis reversal is undoubtedly not foreign to the movement that imposed proprietary ideology in the field of intellectual creations and software (Hettinger 1989). When knowledge is only analysed as result, it becomes an ordinary object. This object can be monetised and dealt in commercial transactions. Then propriety rights take on more and more importance, rather than the cognitive dimensions of learning.

In this configuration, a transfer assumes the existence of qualified actors with separations between them, as well as a project and steps to carry out the transfer. Knowledge has thus been objectified through two means: the invention patent (Almeida 1996) and the scientific publication (Zucker and al. 2002). Academics in search of knowledge diffusion markers have extensively used these two means when studying the transfer of knowledge. Subsequently, the transfer issue turned into a problem of boundaries.

\section{The Challenges of Transfers}

Starting in the 1990s, knowledge transfer became a major issue. The definition given to it is minimal and may even be surprising: 'Knowledge transfer in organisations is the process through which one unit, e.g., group, department, or division, is affected by the experience of another' (Argote and Ingram 2000: 151). This knowledge transfer theme was in fact a translation of resource-based knowledge covering activities related more or less directly to cognitive activities.

Transferring knowledge has become a strategic matter, particularly in regard to the success of mergers between several firms (Doz 1996; Simonin 1999), sharing experience between several subsidiaries of a multinational firm (Hedlund 1994), and in the process of expediting the diffusion of technology between multiple departments (Allen 1979; Amesse and Cohendet 2001). Knowledge can thus be considered an object to be localised and dissociated from its origin of development. For the sake of scientific and technical prudence, knowledge has been reduced to its administrative and codified support: the patent or the scientific publication. As an object it can be designated by a qualifier. This can be broken into technical knowledge or relational knowledge. We can break it down further into certain subtleties, such as explicit knowledge, declarative knowledge, and tacit knowledge. We may also rely on an industrial history of experience feedback from major projects in order to designate an available set of transfer methods.

Knowledge transfer is presented as a strategic challenge. Its direct ancestor is probably the technology transfer developed in the 1970s. Without having established a record of several decades of technology transfer between countries, academics have nonetheless developed this notion of knowledge amply. The influence of the studies developed derives more from economic necessity than from the soundness of the fundamental concepts. Since knowledge is so essential to innovation, it is absolutely necessary to make it available and to acquire it. The methods for acquiring it are less important.

\section{Transfer Difficulties}


Knowledge transfer is an instrument through which a commercial organisation can improve its capabilities. To obtain knowledge, it is necessary to identify the relevant knowledge, to acquire it, and to assimilate it within the organisation. These operations are easy to enumerate; however, in practice they encounter several difficulties.

Three major types of difficulty are encountered when carrying out knowledge transfers (Becker 2001; Lahiri 2010). The time needed and cost of identifying the relevant knowledge within the organisation can be excessive. If it is a question of researching the environment, the difficulties may increase. Then, the actual transfer of knowledge from one unit to another can be tricky. This difficulty is highlighted by the fact that the knowledge is contextualised (Szulanski 1996), and inseparable from its source. It refers back to the question of codifying knowledge. This process is aimed at transforming tacit knowledge into explicit knowledge using shared codes and symbols. It is a process of normalisation, establishing communication choices by determining the information details to focus on. Codification involves transforming a system of action into information that can be used to guide future actions. These actions may involve reflection, analysis, classification, and categorisation of information or transformation of the material. When this information makes sense, it is referred to as explicit knowledge. It is related to tacit knowledge but is only a complement to the former (Zollo and Winter 2002).

The third difficulty can be seen in the significant cultural differences that sometimes exist between pools of knowledge. Herein lies the question of boundaries. It often happens that a firm's management committee decides to acquire knowledge through licenses, technical publications, or even training sessions. But nothing certifies that the agents directly involved in this transfer are able to assimilate the knowledge. The reason for issues is often the cultural distance, in terms of cultural or cognitive boundaries, between the transmitter and receiver of the knowledge transfer. So, it is a question now of either crossing boundaries or exceeding them. This is because the messages sent from the transmitter to the receiver are more or less codified information that is converted into knowledge by the receiver through his intellectual tools, provided that he is interested.

\section{Redefining the Terms of Transfer}

These difficulties are covered in specialised knowledge management studies. In this context, the activity of individuals is recognised as a collection of actions that can guide and structure the acquisition and transmission of knowledge. We then deal with antecedents to the action of disseminating knowledge. This reformulation of the transfer terms has the merit of inserting the activity into its context. But the actual cognitive dimensions of the subject's activity remain largely on the sidelines.

The study by Van Wijk and al. (2008) is probably the most comprehensive in this area. The authors define three major dimensions of transfer antecedents: knowledge, organisation, and social networks. They connect different variables of these three dimensions to knowledge transfer performance. Knowledge is addressed under its more or less ambiguous aspect, which can be a positive or sometimes disruptive factor in the transfer. Second, the organisation is defined according to its classic features: age and size, degree of decentralisation of decisionmaking, and the ability to absorb knowledge. Finally, social networks are the subject of numerous studies. These include social relationships, relationships of trust, and value systems. Other studies also cover incentives for employees to spread knowledge (such as remuneration or career advancement).

Using these three transfer dimensions, we can define the boundaries separating individuals, organisations, units within large organisations and social networks. The difficulty of transfer boils down to the difficulty of crossing a boundary. It is a question of compiling an inventory 
of these difficulties in a market economy approach. In other words, with entities separated from each other, and for which common assets such as language or communication networks do not play a fundamental role.

\section{A Structural Misunderstanding}

We thus see a separation occur between two sets of reflection and we are confronted with two definitions of the boundary. On the one hand, dedicated knowledge management research is analysing the limits of disseminating knowledge. This research is carried out as part of capital development strategies in a private form. Here, the boundary creates a separation. On the other hand, social science research fully integrates the dimensions of learning. This research is primarily interested in the details of learning within a constructivist framework. In this case, the boundary is not so much incurred as it is elaborated by means of the intellectual tools available to humans.

\section{The Separation Boundary}

In his study of knowledge management theories, Snowden (2002) shows how the socialisation, externalisation, combination, internalisation (SECI) model of Nonaka remains the major reference in management models, while his Cartesian references were set aside a few years later by the Japanese approach in terms of ' $\mathrm{Ba}$ ' by the same author (Nonaka and Konno 1998). The Ba is a philosophical Japanese concept that can be considered a "shared space for emerging relationships". This analysis has importance as it helps us understand the strength of the social-historical movement that established this boundary concept. Nonaka's studies show all the subtlety of conceptualisation within an organisation, its socialised dimension and its generalisation into products or manufacturing processes. Nonaka's influence is clearly rooted in Eastern philosophy, referred to as constructivist by Westerners. Despite this culture of learning and of the place given to subjectivity, the distinction between explicit and tacit knowledge was imposed as a tangible reality in scientific writings and teachings of the western world. On this separation a boundary theory has been elaborated. This separation stems from a major epistemic confusion and assumes that what remains unspoken in knowledge is what is not yet explicit. This confusion was thoroughly analysed and criticised by Tsoukas (2009), denying any possibility of separating the tacit and explicit dimensions of knowledge. These are associated with one another as if woven in a braid. Tacit knowledge is not explicit knowledge "internalised, as Nonaka and Takeuchi (1995: 69) claim, nor is it something that a firm may 'lose' during a period of crisis, as Spender (1996: 73) implies. Rather, tacit knowledge is the necessary component of all knowledge; 'it is not made up of discrete beans that may be ground, lost, or reconstituted [...] to split tacit from explicit knowledge is to miss the point - the two are inseparably related' (Tsoukas 2009: 99). If one understands the author, tacit knowledge, which represents the most important aspect of a knowledge transfer, is absolutely not transferable. It cannot be captured or translated explicitly: Tsoukas shows us that the question is in fact badly posed, since tacit knowledge is manifested in what the individual realises. Tsoukas' criticisms address the initial period of Nonaka's work. The latter responded positively (Nonaka \& von Krogh, 2009) highlighting the interaction between tacit and explicit knowledge along a continuum (636 \& seq.)

Evidence shows that the different languages used in different parts of the world are an obstacle to cultural and economic exchange. On a slightly smaller scale, several types of boundaries are defined and referred to as invisible boundaries (Hernes 2004). Most often, physical boundaries designate spaces separated due to very different rules of action. Projects within the same organisation make up such types of segmented spaces. But boundaries are also social and, in this case, these are related to professional attributes. The different professions offer the many roles and representations that employees give to their work. 
Professional identities that develop within an organisation, and all the more so between different organisations, are boundaries that hinder the dissemination of knowledge. Finally, boundaries are in the mind. Ideas and concepts make powerful boundaries between individuals who are trying to understand, collaborate, or even avoid each other.

\section{The Elaborated Boundary}

The second conception of boundaries is inspired by the constructivist epistemology of the social sciences. In economic terms, boundaries are the result of a socio-historical process that installed private property and price competition between disjointed units in the development of $R \& D$, production and distribution capabilities. Furthermore, the market economy is not the only possible economic form. Indeed, the economy of common goods shows another type of organisation of resources and governance (Ostrom 1990). The economy of common goods is seeing a renewed interest in the property sector as well as in the digital economy. A common goods economy is characterised by three complementary elements. It is first either a tangible or intangible resource that is pooled and shared (e.g., open access). It is also a system of property rights attributed to those with guaranteed and protected rights: rights of access, collection, management, transfer, and use of the resource. Finally the common goods economy is distinguished by a governance structure that allows defining rules of action between commoners and towards the resource.

With this form of ownership, collective but limited to a community, the boundary does not have the same characteristics. For example, it may open up the possibility of a noncommercial economy in which information is freely accessible as in the case of Wikipedia.

This boundary conception is completed with the cognitive dimension by the learning approach inherited from Jean Piaget. Biologist, psychologist, and epistemologist, Piaget (1974) distinguished himself by his work on the development of child psychology. Piaget's thinking is valuable in order to break down the knowledge approach in terms of objects. In his theory, each human subject has assimilation structures enabling him to access external data. These structures are the seat of a double process. On the one hand, the subject assimilates sensitive data and information; on the other, he integrates them while accommodating the structures of assimilation. An adaptation thus takes place but not just any adaptation, because by integrating the newness, the subject also develops his adaptability. This complex process is underpinned by a scheme consisting of several faculties that enable the regulation of a subject's activity. This entire dynamic is called equilibration of cognitive structures.

The scheme's concept is highly developed in the areas of the psychology of learning and teaching (Vergnaud 1990). The scheme is structured by four main elements:

- operative invariants of two types: what the subject holds to be true (theorems in-practice) and what he holds to be relevant (concepts-in-practice);

- inferences: collecting information, calculations and controls that allow adjusting the scheme to the variables of the situation;

- rules of action: components that generate sequences of actions leading to the sought result;

- expectations of the results related to the purpose of mobilising the scheme.

In a routine or learning situation, the individual is not in an area cut off from his environment. Here, the concept of cognitive boundaries that separate have a very weak significance. The individual reasons instead according to references to his past experience (operative invariants), then by analogy (inferences and rules of action). The notion of 'double regulation of activity according to situation and subject' is better adjusted to this circumstance (Rogalski 2004). 
We are clearly situated within the practice of knowing. We are interested in the cognitive process as such, and no longer just the organisational context. As a result, the transfer loses its consistency and the boundary appears as a construction by the actors, since perception directs the intention that in turn guides the action. From a methodological point of view, we need to realise that too much separation continues to exist between the various approaches interested in the same study subject. The issue of mobilising knowledge from a management point of view, the analysis of cognitive processes of the construction of meaning and, finally, knowledge engineering approaches are still too far from each other. To try and associate these two conceptions of boundaries is part of the process of reconciling the various knowledge management approaches.

\section{Two Boundary Traditions in the Analysis of Commercial Organisations}

Boundaries separate but they also connect. This is true for territorial boundaries; it is also so for cultural boundaries. Translating from one language to another and transforming one code into another code form boundary crossings that do not alter the separation that remains. Conceivably, boundaries are a sustainable separation. At the same time, spanning them requires resources and arrangements that, in a certain way, establish continuity between spaces that are, in principle, separated.

\section{Boundaries as Separation and Methodological Individualism}

\section{Boundary Practices}

In the field of knowledge management, critical situations are those for which either a significant change has been committed to, or the complexity of resources will likely generate entropy.

Changes concern periods of strategic transition. A change in a firm's business can cause a loss of organisational routines. It can lead to a renewal of the firm's knowledge base. An acquisition or a merger can also represent significant changes. These operations disturb the existing organisation and hierarchies. They can lead to redefining of the information systems, the terms of data retention and the patterns of communication between the various business units of the firm.

Of additional interest is the complexity of resources. This complexity has become the object of studies in terms of social networks, sometimes referred to as strategic networks. This involves, for example, analysing franchise networks, business networks, or R\&D alliances using network analysis methodologies (Inkpen and Tsang 2005).

In situations of change, such work looks at the ability to reassess situations and learning during mergers and takeovers. For example, Bresman and al., (1999) analyse the transfer of knowledge during situations of international acquisition. The firm is analysed as an assembly of distinct professional communities. The question asked is that of the best structures that facilitate the transfer between them. Resources that facilitate the transfer, according to the authors, are the following: face-to-face communication, visits and meetings between partners of different entities, and the codification of knowledge in the form of objects (patents and grey literature). In this work, time is an important resource as it enables better assimilation of the novel.

In the case of internal growth, studies highlight the advantages of socio-technical systems (Bender and Fish 2000). The multinational company Bosch is used as a good example of a transfer based on a powerful sociotechnical system. An intranet system (the third largest in the world) connects 160,000 employees through dozens of subsidiaries, and very strong 
incentives are provided for the mobility of the technicians in order to facilitate the transfer of skills, knowledge and expertise. This kind of experience has often been reported. A successful knowledge transfer cannot be assimilated with a simple transmission of information. It is all about bringing together an efficient information system and a system of varied and frequently affirmed relationships between employees (Davenport and Prusak 1998).

In a more general way, boundary spanning is examined using the structural dimensions of the organisation, along with the cognitive and relational dimensions. To facilitate the crossover, the organisation's structures should focus on employee autonomy, authority must be decentralised, and the number of employees must be sufficiently stable (Orlikowski 2002). The cognitive and relational dimensions are often merged. Lessons from the case studies emphasise the sharing of a vision and collective goals. National or regional cultures must accommodate each other. On a strictly relational level, the risk of misunderstanding must be contained by developing a clear system of incentives.

With the study of networks and social capital, the interest is in individuals and their ability to relate to each other (Gulati and al., 2000; Inkpen 1996; Inkpen and Tsang 2005; Nahapiet and Ghoshal 1998). Through one's various relationships, each person develops a certain amount of social capital. Social capital is thus defined as: 'the ability of actors to secure benefits by virtue of membership in social networks or other social structures' (Portes 1998). Two sizeable questions structure this work at the individual and collective level: how does the dimension of social capital influence an organisation's ability to acquire new knowledge? What are the conditions that facilitate the transfer? The findings of these studies do not fundamentally differ from those of strategic change - the context of communication is crucial. The issue of transfer is placed within the dynamics of the organisation. The social and organisational dimensions are considered to be determining factors. In this context, it is recalled that the transfer of tacit knowledge is more difficult to achieve than that of explicit knowledge (Zander 2002). One is often lead to the conclusion that: 'High care relationships favour both the transfer and creation of knowledge' (Zárraga and Bonache 2005).

\section{Limits of Individualism}

This conception of boundaries has the advantage of defining the difficulties of disseminating knowledge and determining solutions. Its foundations are legal and economic before being cognitive. We can consider that the crossing of boundaries through the transfer of knowledge is never analysed as a true transfer. The reason for this is straightforward: Although an object can be transferred from one business unit to another, knowledge cannot. The cognitive process of boundary spanning is not supported in this approach, simply because entities (individuals, projects, organisations, and networks) are assumed to be separate and separable. This is the big problem behind the shortcomings of the organisational analysis of cognition (Schneider and Angelmar 1993). According to these authors, economic analysis has not integrated all the elements allowing a true study of the dynamics of knowledge. Three levels of analysis have been formulated:

- Cognitive structures (schemes, beliefs, and scenarios): knowledge models, or epistemological structures.

- The cognitive process: the particular manner in which knowledge is selected, organised, transformed, stored, and used.

- Cognitive styles that highlight individual, collective, and organisational differences in the way information is processed.

Are these levels effective in order to explain the main reasons for boundary building? 
In fact, this inventory is not sufficient because we could reconstruct many other separations between various structures, different processes and contrasting styles. Therefore, we must look even further, or rather below the level of the units.

In separations between units, language is not taken into account. Whether natural languages or specialised languages with specific codes, these are still common elements that occupy the economic and social space. If the economic units obtain an individual status by law (private property) and by market mechanisms (price), they cannot be isolated in cognitive terms. This observation and resulting analysis fall within the process of individuation (Simondon 1989). The two philosophical conceptions of individuation are opposed: the substantialist and monist conception considers a being as based on itself; the bipolar or hylomorphic conception considers the individual as engendered by the meeting of form and matter. In other words, 'we must make a reversal researching the principle of individuation, by considering as primordial the operation of individuation from which the individual comes into existence and from which he reflects the unfolding, the regime, and finally the modalities in his character' (Simondon 1989: 12). Thus, the individual and his environment must be considered in order to analyse a process of individuation. This process is both psychological and social. The individual needs the group to constitute himself; he becomes an autonomous entity through the group to which he is connected. This is referred to as transindividuation.

The separate conception of entities in this way loses its analytical power. We can consider its complement.

\section{The elaborated boundary}

\section{Mechanisms, Learning and continuity}

Among the many empirical demonstrations of a boundary that is not a separation but a continuity, two processes are very instructive: tutoring and boundary objects. Tutoring has functional qualities that are not very well known, whereas boundary objects have the benefit of extensive literature.

Tutoring or mentoring is a common practice in organisations. It may fall within formal procedures or develop autonomously within professional communities. It is a learning process intended to advance the knowledge of a new employee or to transmit the knowledge of an employee leaving the organisation. This learning situation creates an interaction in which each of the actors (expert and novice) can learn.

Brassac (1994, 2008) developed a methodology to help in the transmission of experience using a social psychology approach. In his method, knowledge acquisition is a process in which at least two actors are jointly responsible: the tutor and the learner. This process unfolds within a set of social interactions made up of discursive exchanges, gestural manoeuvres, and by manipulating machines. For the actors, it is a matter of maintaining these interactions; there is not, in itself, a transfer of knowledge. The process is a joint construction of meanings that are meant to be used and appropriated by the learner. To facilitate this appropriation, Brassac developed a methodology that integrates the largest possible amount of data from the context of interaction. According to the author, the recordings of an interview and their analysis are not enough. The tutor's lessons and the learner's apprehension thereof must not be disconnected. Nor should the expression of expertise be abstracted from its concrete place of realisation. Finally, one should not prevent the two actors from graphically representing their work with graphs.

Thus, the various actors are provided the opportunity to develop a range of direct relationships: relationships to knowledge, hesitations, oversights, dependence on documents, 
and limitations. The ability to question, to point out inconsistencies, and offer new opportunities is maintained. The prospect of sharing is therefore related to the fact that knowledge is distributed between the tutor and the artefacts (documents, equipment, and physical spaces). According to the author, a good strategy involves focusing on going back and forth between the different modalities of knowledge collection. These iterations promote diversity and redundancy that are factors towards consolidating learning.

This method of tutoring does not separate the tutor from the learner, or the expert from the novice. However, it allows the identification of discrepancies between the performative statements and experiences. On this basis the actors are qualified to produce recommendations and reformulations for the performance.

The second practice is very present in design offices and cooperative design. In these areas, knowledge is just as localised in the problems that arise as in the practices of individuals. In their design work, individuals work with objects such as numbers, technical notes, tools and machines, as well as results such as sales contracts, prototypes, and purchase orders. These objects create a punctuation in the time of the design process and thus a boundary.

The object is the concrete form of the boundary between two worlds. 'Boundary objects are those that are both plastic enough to adapt to the local needs and constraints of the several parties employing them, yet robust enough to maintain a common identity across sites' (Star and Griesemer 1989: 393). These objects are apparently weakly structured and take on meaning during interactions. While expressing a boundary, they are somewhat receptive to different arrangements proposed by the participants. At all times, the design is simultaneously fixed and also ready to evolve.

Carlile (2002) focuses on the difficulties of collaboration between engineers and other specialists as they work within their respective fields. Rather than focusing on knowledge flows, he studies the objects that participate in attempts at mutual comprehension. The objects are vectors of representations because they are oriented by an intention or a goal stemming from a sociotechnical-economic world. For example, a drawing represents the dependencies between different designers as well as its consequences in terms of the work's progression.

Carlile defines three main characteristics that can facilitate knowledge transfer (Carlile 2002: 451-452):

- 'A boundary object establishes a shared syntax or language for individuals to represent their knowledge' (syntax),

- 'An effective boundary object... provides a concrete means for individuals to specify and learn about their differences and dependencies across a given boundary' (semantic),

- 'An effective boundary object facilitates a process where individuals can jointly transform their knowledge' (pragmatic).

Holford (2016) develops, in this sense a constructivist theory of boundary objects. Objects do not pre-exist but emerge by means of intellectual constructions, enactments, agency mechanisms (Barad 2007) and situated actions (Suchman 2006). The author suggests abandoning the idea of a duality between the subject and object in favour of an intrainteraction process. This process is attached to the mental work of the subject. It participates in boundary construction and constitutes a credible alternative to the dichotomous 'subjectobject' or 'results-process' approaches.

\section{The Work of Creating the Boundary: What Is a Mechanism?}

This boundary creation is not completely opposed to the idea of boundaries as a separation. Instead, it introduces a final concept that one must consider: the mechanism. 
This concept was developed in the mid-1970s through the work of the French philosopher Michel Foucault (1976). He defines the mechanism as the network that can be traced between the various heterogeneous elements that progressively form a whole, consisting of discourses, institutions, laws, physical areas, administrative rules, scientific statements, or even philosophical and moral propositions.

For organisations, and in the cognitive domain, mechanisms are defined as organised, finalised groupings of intellectual objects structured among themselves and distributed for the production of goods or knowledge (Poitou 1995, 1997). Intellectual objects are able to elicit practical and technical intellectual steps inherent in artificial objects, such as automated equipment and machines. These approaches use the resources of analytical tool. Thus, the individual works within a very diverse set of resources using his mental tools.

For commercial organisations, these mechanisms are set up to meet intensive innovation needs. A typology is provided in this area by Charue-Duboc $(2006,2007)$. These mechanisms are developed to promote learning between projects, learning with external entities or even learning by exploration. For example, mechanisms with external entities are considered 'boundary spanners' (Allen and al. 1979), and 'absorptive capacity' (Cohen and Levinthal 1990) is necessary to absorb external knowledge. Recent developments identify two models: The first involves reproducing within the firm the scientific divisions of the academic world in order to facilitate relations with the outside. The second model focuses on specific industrial problems and tends to unify different academic fields. Within a department, different skills are combined to build expertise on themes common to several projects.

But these mechanisms are never stable. They are constantly recomposing themselves in time and space. The individual at work does not need to use all available knowledge. This makes variety and discontinuity possible within human activities, as well as the prospect of cooperation. Knowledge is located in the working environment, and distributed among all the technical elements composing it, and with the operators. This distribution is not immutable; it is constantly renewed according to the needs of the various phases of operation and cooperative interactions between agents (Poitou 1995, 1997).

Although the mechanism is a concept that describes fairly well the elaboration of boundaries, it should be limited. What could be the density of a mechanism? In this field of study, opposition developed between two analyses (Shinn 1997). One emphasises the rigidity of boundaries between scientific disciplines: Epistemologies as well as the historical elaboration of scientific institutions have set up particular mechanisms of coordination in the scientific and technical world. The other approach highlights a 'seamless web', that is, a powerful restoration of harmony between disciplines. It is anchored in the actor-network theory and assumes a high density and a strong extension of the mechanism. Shinn, on the other hand, shows that there can exist a convergence between different scientific communities but that it takes place using the resources offered by the division of labour between disciplines. So, boundaries play their part. This does not prevent high levels of knowledge hybridisation between scientific disciplines, between science and technology, between the firm and external entities.

\section{Boundaries of Information and Knowledge-Sharing}

Here we examine the boundaries of knowledge in the context of non-commercial organisations. We illustrate the boundaries of information-sharing in the case of Wikipedia. This website went up online in 2001 organised on the wiki principle that everyone can openly modify everything, anytime and anyhow. From a few hundred initial contributors, Wikipedia quickly grew and became the biggest wiki ever built. In its English version, as of the date of 
this writing it holds over 5 million articles and has more than 30 million contributors, of which approximately 134,000 are active every month. Claiming the production of encyclopaedic content, Wikipedia introduced a break with classical encyclopaedias, where an author had to be academically recognised to be entrusted with the drafting of an article. In the case of Wikipedia, even a first-year sociology student can edit the page corresponding to sociology. This has not failed to create several controversies about the reliability of the knowledge found there. Among all these works, Zhang and al. (2010) raise the question of whether the experts of a specific area are a source that is significantly used by wikipedians writing the corresponding pages. The methodology is based on a comparative survey of Wikipedia articles on terrorism, and a database of individuals, events, and terrorist networks put together by professional analysts. Giles (2005) proposes a comparison between Wikipedia and Britannica on similar articles. Parallel to these discussions, Reagle (2010) offers a very intricate view of collaborative culture as the foundation of interactions between contributors. This latter work enables immersing ourselves in the daily interactions that produce and reproduce the wiki. We will put aside this discussion now in order to focus on how contributors build boundaries in the corpus of documents that they produce.

We briefly explore the project's central concept, which replaces the notion of category in an encyclopaedia such as the Britannica. These projects at once provide separations but also powerful tools for drawing up boundaries.

Wikipedia's projects - or 'WikiProject' - are local spaces dedicated to social construction of governance. For instance, the page 'Wikipedia:WikiProject Economics' lets us see a different regulation of contribution than the page 'Wikipedia:WikiProject Philosophy'. Of course, this means that economics articles are not regulated the same way as those of philosophy. In that way, projects are more than the classical 'category', but at the same time, they are a regulation tool that allows different contributors interpret - and respect - the same rules differently.

\section{The Boundaries of a Wiki}

The word encyclopaedia is forged by the contraction of the Greek enkyklios, which refers to the circle and its construction, and paedia, which designates education or transmission. Throughout history, the encyclopaedists set themselves the goal of bringing together in a book, a library, or a database all knowledge worthy of being used in the pedagogy of new generations. The contents of these works gives us a clear view of knowledge as the foundation of civilisations. It was thus during the Song Dynasty, which gathered together in the largest encyclopaedic work of China all the knowledge necessary for the instruction of the high officials of its administration. In the same way, there were Arabic-Muslim encyclopaedias, which included rules of propriety with exegeses. Rey (2007) offers a vast history of encyclopaedism, situating it in a millennial process. This same process led us in the West during the Renaissance to a secularisation of encyclopaedias. Formerly created as educational tools for the use of the clergy, they became systematic inventories organised according to classifications in which God seems to have stepped aside. The most famous of these classifications, proposed by Francis Bacon in his Novum Organum, is still used today in reference encyclopaedias such as the Britannica. We need to go beyond the scope of this discussion to show the response of this new classification scheme to the upheavals of the time: the renewal of trade, the discovery of America, and the advancement (already!) of communication technology.

Except for a few details, Wikipedia is not innovative in terms of its categories. In the English version, articles are divided into the following groups: arts, biography, geography, history, mathematics, sciences, society and technology. Here we find classification categories to which academic eyes are rather accustomed. It seems to us that the real difference between 
the Wikipedia project and the categories of classical encyclopaedias lies not in their titles but in their construction methods. An article in the Britannica is likely commissioned by an editorial board to an academic, then inserted into an already determined category. Conversely, Wikipedia's articles on the arts are created by the personal initiative of a motivated contributor, which does not rely on a preestablished order of categories. They are then attached to the relevant art project, whose summary is built after the fact.

In terms of boundaries, we find in the gradual differentiation of projects an elaboration process of Wikipedia's internal boundaries. At the beginning, we had articles that tell us about the Mona Lisa and the Higgs boson. It was only later that these articles were attached to collections that refer to the arts and physics. It is also interesting to note that the projects fit together like Russian dolls. For example, in the science project we find a physics project, itself divided into space, time and cosmology projects. Articles can be linked to several projects, and here we find the theories of Leuf and Cunningham (2001), according to which the computerisation of knowledge management moves us away from categorisation towards tagging. The category puts itself in a box, the tag highlights a character, and indexes the corresponding entities.

This organisation led to an information governance which is one major criterion (Coriat 2015) that allows to qualify Wikipedia as a commons. Forte and al. (2009) analyse in detail the decentralised nature of Wikipedian governance. The wikiproject economics is not governed in the same way as the wikiproject philosophy or the its physics. Without entering into these subtleties here, we invite the reader to browse these web pages and observe the different management tools in place.

\section{Separations that Develop Boundaries}

Consider now a very simple story replayed at least a hundred times every day on Wikipedia: two articles, for example one on sociology and another on economy are both put together, each with their contributors. Perhaps also the contributors are working on both one and the other. At a point in their development, one of these two articles will create a hyperlink to the other. This banal operation commonly used by many contributors might be interpreted as establishing a boundary between the two articles. Therefore, at least three lessons can be learned about the construction of boundaries within shared information.

First lesson: shared information is inseparable from its delivery method (Coriat, 2015). Through its interface, Wikipedia offers ways within the reach of any contributor to create links between pages. First, with a mark-up system, then today with a visual editor, simplifying the task yet a little more. To create a link between Howard Becker and a sociology article, it is only necessary that the word Howard Becker be mentioned at least once in the sociology article. And, of course, it is possible for anyone to add the link. We can even go a little further by mentioning the red links to which Wikipedia users are accustomed. When a hyperlink appears in red, it points to a page that has not yet been created. This MediaWiki feature has proven rather effective in stimulating the creation of new articles.

Second lesson: for a link to exist and persist, the two articles it links must continue to exist and persist. We can only develop a boundary between distinct elements. Although this observation may seem trivial, it implies that the elaboration of a boundary is a powerful consolidation vector for wiki. Strictly speaking, when consulting a wiki page we see what has been written by a contributor. But above all, we only see what was not erased by the contributors who modified the page afterwards.

Third lesson: the article's development implies the creation of links. McGuinness and al. (2006) show that the articles assessed by the contributors of featured articles are also the most 
cited, that is, the ones with the most contributors develop the most boundaries. The featured articles are selected through a voting procedure in which the article can be rated by any other contributor. If it receives more than $75 \%$ favourable votes, it is then promoted with a label made visible using a small star below its title.

These three lessons lead us to believe that, more than the transfer of knowledge, it is the boundaries that must be multiplied in order for the sharing of information to be able to function. To pursue knowledge transfer from one contributor team to another would be irrelevant in the wiki context. To take just one example, a mention from the sociology article probably does not belong in the economy article. At most, a presentation of standardised information can be exchanged, for example, in the presentation of bibliographic references or illustrative documents. An encyclopaedia needs to differentiate areas in order to exist as such. However, linking them together is a very effective way of making a cognitive map appear around the object of the article. It is this tension that makes the hyperlink. And it is for this reason that it has taken such an important place within Wikipedia.

Silva and al. (2011) show that the distribution of the links between the different projects can vary. While biology and medicine projects saw their articles strongly linked to each other, the opposite was true for articles related to physics and mathematics. This result echoes the decentralisation of governance that we mentioned: In addition to presenting themselves differently to the contributors who draft them, projects lead to a structural differentiation of the pages, beyond their content.

On the other hand, one does not have to be a data scientist to understand that articles will bind together all the more readily if they are included in the same project. If we write an entire article on sociology, it is likely the name of Howard Becker will be mentioned. The converse is true: it is even more difficult to see how an article on Howard Becker could not make mention of sociology. In addition, the Howard Becker article will probably be attached to the social science project. We therefore find two articles linked within the same project.

Through these two examples, we wanted to show that the conceptual framework outlined in the first part is operating beyond the distinction between the commercial and non-commercial realms. Opening our sight to the non-commercial unities has not yet be very much done. But with very short and quite exploratory analysis, we attempt to show that it can be heuristic.

\section{Conclusion}

At the end of this analysis, we should first like to emphasise the interest in historical and reflexive analysis brought to the concepts of knowledge management. Such an analysis can illuminate the construction of real cycles of scientific interest mixed with economic interests.

We then highlight the genealogy of the two different conceptions of boundaries. Taken one after the other, these two concepts may seem very different but they are in fact complementary. Boundary separation may suggest that the alternatives are very limited, and that only economic objectives allow the forcing a passage. On the contrary, the boundary as an elaboration replaces the terms of the analysis by recalling the role of learning processes. The boundary is then considered in terms of knowledge hybridisation.

This hybridisation emerges clearly in the semantic processing implemented within information sharing such as on Wikipedia. This allows us to finally emphasise two major ways of relating to knowledge. For commercial organisations, knowledge is a strategic resource and a commodity. An analysis of boundary spanning is very closely linked to the issue of private property. On the other hand, in the case of sharing, knowledge is a cognitive and social resource, dissemination of which can be guaranteed by a negotiated collective ownership. 


\section{References}

Allen, T.J., Lee, D.M.S., \& Tushman, M.L. (1979). "Technology transfer as a function of position in the spectrum from research trough development to technical services", Academy of Management Journal, 22, 4: 694-708.

Almeida, P. (1996). «Knowledge sourcing by foreign multinationals: patent citation analysis in the U.S. semiconductor industry. Strategic Management Journal, 17, winter, 155-165.

Amesse, F. \& Cohendet, P. (2001). "Technology Transfer revisited from the perspective of the knowledge-based economy", Research Policy, 30, 9: 1459-1478.

Argote, L. \& Ingram P. (2000). "Knowledge transfer: A basis for competitive advantage in firms". Organizational Behavior and Human Decision Processes, 82: 150-169.

Barad, K. (2007). Meeting the Universe Halfway: Quantum Physics and the Entanglement of Matter and Meaning. Duke University Press. Durham, NC.

Becker M.C. (2001) "Managing dispersed knowledge: organizational problems, managerial strategies and their effectiveness", Journal of Management Studies, 38, 7: 1037-1051.

Bender, S. \& Fish, A. (2000). "The transfer of knowledge and the retention of expertise: the continuing need for global assignments", Journal of Knowledge Management, 4, 2: 125137.

Blumer, H. (1966). "Sociological implications of the though of George Herbert Mead", American Journal of Sociology, 71, 5: 535-548.

Brassac, C. (1994). "Speech acts and conversational sequencing”, Pragmatics and Cognition, 2, 1: 191-205.

Brassac, C., Fixmer, P., Mondada, L. \& Vinck, D. (2008). "Interweaving Objects, Gestures, and Talk in Context". Mind, Culture, and Activity, Taylor \& Francis (Routledge), 15, 2: 208-233.

Bresman, H., Birkinshaw J., \& Nobel R. (1999). "Knowledge Transfer in International Acquisitions" Journal of International Business Studies, 30, 3: 439-462.

Carlile, P.R. (2002). "A Pragmatic View of Knowledge and Boundaries: Boundary Objects in New Product Development”, Organization Science, 13, 4: 442-455.

Charue-Duboc F. (2006). "A Theoretical Framework for Understanding the Organization of the R\&D Function. An Empirical Illustration from the Chemical and Pharmaceutical Industry", International Journal of Innovation Management, 10, 4: 455-476.

Charue-Duboc F. (2007). "Dynamiques des connaissances et dynamique d'innovation", Réalités Industrielles, mai, 32-37.

Cohen, W.M. \& Levinthal, D. (1990). "Absorptive capacity: A new perspective on learning and innovation", Administrative Science Quarterly, 35, 1: 1-25.

Cook, S.D.N. \& Brown, J.S. (1999). Bridging Espistemologies: The Generative Dance Between Organizational Knowledge and Organizational Knowing, Organization Science, 10, 4: 381-400.

Coriat, B. (Éd.). (2015). Le retour des communs et la crise de l'idéologie propriétaire. Paris: Les liens qui libèrent.

Davenport, T.H. \& Prusak, L. (1998). Working Knowledge: How Organizations Manage What They Know, Harvard Business School Press, Boston, MA. 
Doz, Y. (1996). "The evolution of cooperation in strategic alliances: Initial conditions or learning processes?” Strategic Management Journal, 17 (Special issue): 55-84.

Forte, A., Larco, V., \& Bruckman, A. (2009). Decentralization in Wikipedia governance. Journal of Management Information Systems, 26, 1: 49-72.

Giles, J. (2005). Internet encyclopaedias go head to head. Nature, (438).

Grant, R.A., (1996). "Toward a Knowledge-Based Theory of the Firm". Strategic Management Journal, Vol. 17, Winter Special issue, p. 109-122.

Gulati, R., Nohria, N. \& Zaheer, A. (2000). "Strategic Networks", Strategic Management Journal, 21: 203-215.

Hedlund, G. (1994). "A model of knowledge management and the N- form corporation." Strategic Management Journal, 15 (special issue): 73-91.

Hernes, T. (2004). "Studying Composite boundaries: A Framework of analysis", Human Relations, 57: 9-29.

Hettinger, E. C. (1989). Justifying Intellectual Property, Philosophy and Public Affairs, 18, 1, p.31-52.

Holford, W. D. (2016). Boundary constructions as knowledge flows within and between work groups. Knowledge Management Research \& Practice, 14(1), 4-14.

Inkpen, A.C. \& Tsang E.W.K. (2005). "Social Capital, Networks, and Knowledge Transfer", Academy of Management Review, 30, 1: 146-165.

Inkpen, A.C. (1996). "Creating knowledge through collaboration". California Management Review, 39: 123-140.

Lahiri, N. (2010). "Geographic distribution of R\&D activity: how does it affect innovation quality?" Academy of Management Journal, 53, 5: 1194-1209.

Leuf, B., \& Cunningham, W. (2001). The Wiki Way: Quick Collaboration on the Web. Boston: Addison-Wesley Professional.

McGuinness, D. L., Zeng, H., Da Silva, P. P., Ding, L., Narayanan, D., \& Bhaowal, M. (2006). Investigations into Trust for Collaborative Information Repositories: A Wikipedia Case Study. MTW, 190.

Nahapiet J. \& Ghoshal S., (1998). "Social capital, intellectual capital, and the organizational advantage", Academy of Management Review, 23, 2: 242-266.

Nonaka, I. \& Konno N. (1998). "The concept of "Ba: Building Foundation for Knowledge Creation." California Management Review, 40, 3: 40-54.

Nonaka, I. \& Takeuchi, H. (1995). The Knowledge-Creating Company: How Japanese Companies Create the Dynamics of Innovation, Oxford University Press Inc.

Nonaka, I., \& Von Krogh, G. (2009). "Tacit Knowledge and Knowledge Conversion: Controversy and Advancement in Organizational Knowledge Creation Theory". Organization Science, 20, 635-652.

Orlikowski, W.J. (2002). "Knowing in practice: Enacting a collective capability in distributed organizing”. Organization Science, 10: 249-273.

Ostrom, E. (1990). Governing the commons. The evolution of institutions for collective action. Cambridge University Press.

Piaget J. (1974). La prise de conscience, Paris : Presses Universitaires de France. 
Poitou, J.P. (1995). "Documentation is Knowledge: An Anthropological Approach to Corporate Knowledge Management", in Barthès J.P. (Ed), Proceedings of the Third International Symposium on the Management of Industrial and Corporate Knowledge. Compiègne : 91-103.

Poitou, J.P. (1997). « La gestion collective des connaissances et la mémoire individuelle », in J.M. Fouet (Ed.) : Connaissances et savoir-faire en entreprise. Intégration et capitalisation. Paris : Hermès : 157-178.

Portes, A. (1998). "Social capital: Its origins and applications in modern sociology". Annual Review of Sociology, 24: 1-24.

Reagle, J. M. (2010). Good faith collaboration: The culture of Wikipedia. MIT Press.

Rey, A. (2007). Miroirs du monde: Une histoire de l'encyclopédisme. Paris: Fayard.

Rogalski, J. (2004). "Psychological analysis of complex work environments", in M. Fisher, N. Boreham \& B. Nyham (Eds.), European perspectives on learning at work: the acquisition of work process knowledge, (pp. 218-236). Luxembourg : CEDEFOP 56.

Schneider, S.C. \& Angelmar, R. (1993). «Cognition in organizational analysis: who's minding the store? », Organization Studies, 14, 3: 347-374.

Shinn, T. (1997). "Crossing boundaries: the emergence of research-technology communities" in Henry, E., Loet L. (eds.). Universities and the global knowledge economy: a triple helix of university-industry-government relations, London, Cassel Academic Press, pp. 85-96.

Silva, F. N., Viana, M. P., Travençolo, B. A. N., \& Costa, L. da F. (2011). Investigating relationships within and between category networks in Wikipedia. Journal of Informetrics, 5, 3: 431-438.

Simondon, G. (1989). L'individuation psychique et collective. Paris : Editions Aubier. First edition 1964.

Simonin, B.L. (1999). "Ambiguity and the process of knowledge transfer in strategic alliances », Strategic Management Journal, 20, 7: 595-623,

Snowden, D. (2002). "Complex acts of knowing: paradox and descriptive self-awareness" Journal of Knowledge Management, 6, 2: 100-111.

Star, S.L \& Griesemer, J.R. (1989). "Institutional Ecology, 'Translations' and Boundary Objects: Amateurs and Professionals in Berkeley's Museum of Vertebrate Zoology, 190739". Social Studies of Science, 19, 4: 387-420.

Suchman, L., (2006). Human-Machine Reconfigurations: Plans and Situated Actions (2nd edition). Cambridge ; New York: Cambridge University Press.

Szulanski, G., (1996). «Exploring internal stickiness: Impediments to the transfer of best practice within the firm », Strategic Management Journal, 17, Special Issue: 27-43.

Teece, D.J. (2009). Dynamic Capabilities and Strategic Management: Organizing for Innovation and Growth, Oxford University Press.

Tsoukas, H., (2009). "The firm as a distributed knowledge system: A constructionist Approach" in Tsoukas, H, Complex knowledge. Studies in Organizational Epistemology. Oxford University Press: 94-116.

Van Wijk, R., Jansen, J. J. P., \& Lyles, M. A. (2008). "Inter- and Intra-Organizational Knowledge Transfer: A Meta-Analytic Review and Assessment of its Antecedents and Consequences". Journal of Management Studies, 45(4): 830-853. 
Vergnaud, G. (1990). «La théorie des champs conceptuels », Recherche en didactique des mathématiques, 10, 2/3, 133-170.

Vygotski, L.S. (1934, 1985). Thought and Language, Cambridge (Mass.), The MIT Press.

Weick, K.E. \& Bougon, M.G. (1986). "Organisations as cognitive maps: charting ways to success and failure", in H.P. Sims, J et Gioia, D.A, The thinking organization : Dynamics of organizational social cognition, Jossey-Bass, San Francisco: 102-135.

Weick, K.E. \& Roberts, K.H. (1993). "Collective Mind in Organizations: Heedful Interrelating on Flight Desks", Administrative Science Quaterly, 38, 3: 357-381.

Weick, K.E., (1969). The Social Psychology of Organizing ( $2^{\circ}$ ed), Reading Mass, Addison Wesley.

Wernerfelt, B. (1984). «A Resource-based View of the Firm. », Strategic Management Journal, vol. 5, $\mathrm{n}^{\circ}$ 2, p. 171-180.

Zander, U. (2002). "The formation of International Innovation Networks in the Multinational Corporation: an Evolutionary Perspective", Industrial and Corporate Change, 11, 2: 327353.

Zárraga, C. \& Bonache, J. (2005). "The impact of team atmosphere on knowledge outcomes in selfmanaged teams". Organization Studies 26, 5: 661-681.

Zhang, Y., Sun, A., Datta, A., Chang, K., \& Lim, E.-P. (2010). Do Wikipedians Follow Domain Experts?: A Domain-specific Study on Wikipedia Knowledge Building. In Proceedings of the 10th Annual Joint Conference on Digital Libraries (p. 119-128). New York, NY, USA: ACM.

Zollo, M., \& Winter, S. (2002). Deliberate learning and the evolution of dynamic capabilities. Organization Science, (May-June), 339-351.

Zucker, L., Darby, M., \& Armstrong, J. (2002). Commercializing knowledge: university science, knowledge capture, and firm performance in biotechnology. Management Science, $48,1,138-153$. 